Article

\title{
Personality Effects on the Endorsement of Ethically Questionable Negotiation Strategies: Business Ethics in Canada and China
}

\author{
Xiaoyi Liu ${ }^{1}$, Zhenzhong Ma ${ }^{2,3, * \mathbb{C}}$ and Dapeng Liang ${ }^{1, *}$ \\ 1 School of Management, Harbin Institute of Technology, Harbin 150001, Heilongjiang, China; \\ 14b310012@hit.edu.cn \\ 2 School of Business, Nanjing Audit University, Nanjing 211815, China \\ 3 Odette School of Business, University of Windsor, Windsor, ON N9E 4Z4, Canada \\ * Correspondence: maz@uwindsor.ca (Z.M.); ldp0920@hit.edu.cn (D.L.)
}

Received: 25 March 2019; Accepted: 21 May 2019; Published: 1 June 2019

\begin{abstract}
This study explores personality effects on the endorsement of ethically questionable negotiation strategies in Canada and China. With a sample of over 400 business professionals, this study examines the relationship between the Big Five personality traits and the perceived appropriateness of five categories of negotiation strategies in the two cultures. The results show that the Big Five personality traits strongly affect the endorsement of ethically questionable negotiation strategies (EQNS) both in Canada and in China, but in different ways. For Canadian negotiators, individuals high in conscientiousness, extraversion, and openness are more prone to use EQNS, and individuals high in emotional stability and agreeableness are less likely to use them. For negotiators from Mainland China, only agreeableness and emotional stability are negatively associated with the endorsement of the EQNS. Implications for research on business ethics and for negotiation practitioners and policymakers are then discussed.
\end{abstract}

Keywords: Canada; China; business ethics; negotiation strategies; personality; ethically questionable negotiation strategies (EQNS)

\section{Introduction}

Ethicality is an important aspect of the negotiation process (Ma, 2010 [1]; Rivers \& Lytle, 2007 [2]; Robinson et al., 2000 [3]; Volkema, 2004 [4]). Negotiators often need to understand what negotiation strategies are ethically appropriate and what are not in order to avoid misunderstanding and improve negotiation effectiveness. Decades of negotiation research has assumed that personalities are relevant to the understanding of the dynamic process of negotiation encounters (Barry \& Friedman, 1998 [5]; Thompson, 1990 [6]), and research has also shown that various individual characteristics affect negotiator's attitudes toward ethically questionable negotiation strategies (Adler, 2007 [7]; Ma, 2010 [1]; Volkema, 1998 [8], 1999 [9], 2004 [4]; Volkema \& Fleury, 2002 [10]). However, previous studies on negotiation and negotiation ethics have largely focused on isolated traits or special negotiation contexts (O'Fallon \& Butterfield, 2005 [11]) and none of them have used a broad structure of personality to examine the personality effects, leading to inconclusive evidence for the dispositional influence on negotiation ethics (Lewicki \& Robinson, 1998 [12]; Lewicki et al., 2007 [13]). It is, therefore, essential to use well-reasoned personality variables to further examine dispositional determinants of ethical attitudes and behaviors in order to help explore the antecedents and effects of negotiation ethics (Volkema, 2004 [4]). This study is intended to draw upon a comprehensive model of personality structure to examine dispositional influence on the tendency to use ethically questionable negotiation strategies (EQNS). 
Previous studies have also suggested that a number of factors, including personality/demographic factors, situational/context factors, cultural factors, and economic factors, are possible predictors of ethical attitudes and behaviors in the international context wherein negotiators often come from different cultural backgrounds and, miscommunication frequently occurs (Adler \& Gundersen, 2008 [14]; O'Fallon \& Butterfield, 2005 [11]; Volkema, 1999 [9], 2004 [4]). However, current studies in this field often limit their samples to North American populations. Scholars have begun to articulate the importance of expanding samples beyond the North American context, in particular, the importance of using samples from China (Ma, 2009 [15]; Volkema, 2004 [4]), one of the most important emerging markets and probably the next economic superpower (Ip, 2009 [16]; Lam \& Shi, 2008 [17]; Lan, et al., 2009 [18]). Chinese culture is one of the representative cultures from the East where there are a large number of cultural barriers that make it extremely difficult to impose Western norms and ethical standards (Ma, 2010 [1]). In addition, China has become one of the preferred emerging markets and the most favored foreign direct investment destinations. The Sino-West business negotiation has become a key component of Sino-West business relationships. Due to a large number of multinationals corporations entering China's market, negotiating with the Chinese has presented a great challenge to these companies, and Chinese culture is a powerful test of the universalistic aspiration of Western theory on business ethics. Knowledge about negotiation ethics in China will be able to generate insights about Chinese business mindsets and increase Western companies' chances of success in the Chinese market (Ghauri \& Fang, 2001 [19]).

This study seeks to help address this issue using the cultural context theory with samples from Canada and China (Hall, 1976 [20]; Kittler, Rygl, \& Mackinnon, 2011 [21]). Cultural context reflects the degree of sensitivity to communication contexts, where individuals from high-context cultures are more sensitive to these communication contexts (Hall, 1976 [20]; Ma, 2010 [1]), and research has shown that cultural context affects the way negotiators perceive the particulars of a context, which further affects negotiators' behavioral responses and negotiation tactics (Ma, 2010 [1]). The study also uses the Big Five scale to explore personality effects on the endorsement of EQNS within these two cultures. A comparison of dispositional determinants of EQNS in Canada and China based on the cultural context theory will enrich our understanding of the unique influence of individual personality on the endorsement of EQNS across cultures, help identify the distinct characteristics of Chinese business ethics, and further facilitate the promotion of a commonly accepted ethical standard across the globe (Banai, Stefanidis, Shetach, \& Ozbek, 2014 [22]; Stefanidis, Banai, \& Richter, 2013 [23]). The findings of this study will be able to help researchers, policymakers, and negotiation practitioners learn more about individual differences in EQNS, how attitudes toward those tactics/behaviors might change across cultures, and the relative effectiveness of a universal standard of ethics on people from different backgrounds with different personalities (Rivers \& Lytle, 2007 [2]; Volkema, 2004 [4]).

\section{Conceptual Background and Hypothesis}

Ethics refers to the moral principles or values that govern a group of people (Volkema, 2004 [4]). These principles and values distinguish right from wrong, good from evil, and thereby guide individuals' attitudes and behaviors in their personal and professional decisions (Alas, 2006 [24]; Ma, 2007 [25], 2010 [1]; Volkema, 2004 [4]; Volkema \& Fleury, 2002 [10]). The past decades have shown increased interest in understanding various ethical standards and relevant factors that may affect these principles (Rivers \& Lytle, 2007 [2]; Volkema, 2004 [4]; Volkema \& Fleury, 2002 [10]). The majority of the research focuses on certain factors including personality/demographic factors, economic factors, situational/context factors, and cultural factors ( $\mathrm{O}^{\prime}$ Fallon \& Butterfield, 2005 [11]; Tenbrunsel \& Smith-Crowe, 2008 [26]; Volkema, 1999 [9], 2004 [4]). Much of the early research on business ethics focused on demographic factors such as age, gender, work experience, education, nationality, and religion (O'Fallon \& Butterfield, 2005 [11]; Tenbrunsel \& Smith-Crowe, 2008 [26]). For example, a considerable amount of literature has shown that personal factors such as age and gender affect ethical attitudes and behaviors in negotiations. Women often maintain higher ethical 
standards than men, and older individuals maintain higher ethical standards than younger ones (Ma, 2010 [1]; Volkema, 2004 [4]). Other studies have found that cultural factors are also very important in understanding ethical decision making (Ma, 2010 [1]; Rivers \& Lytle, 2007 [2]; Volkema \& Fleury, 2002 [10]). In his nine-country empirical study, Volkema proved that Hofstede's cultural dimensions, as well as the GDP per capita, predicted variance in perceived appropriateness or likely use of one or more of the five categories of negotiation strategies (Volkema, 2004 [4]).

Personality factors including locus of control, risk propensity, ethical ideology, Machiavellianism, and competitiveness have also been investigated for their impact on negotiation ethics ( $\mathrm{O}^{\prime}$ Fallon \& Butterfield, 2005 [11]; Tenbrunsel \& Smith-Crowe, 2008 [26]). For instance, ethical ideology (idealism vs. relativism) has been found to affect decisions in ethically questionable situations. Idealism is negatively related to the use of unethical strategies, while relativism is positively related to such use (Al-Khatib et al., 2005 [27]; Banas \& Parks, 2002 [28]). However, while previous studies have generated impressive negotiation literature on the relationship between individual dispositional factors and ethical attitudes and behaviors, current negotiation ethics research remains fragmented on whether overall personality affects individuals' ethical attitudes and behavior in negotiations. The inconsistency in previous research is due to the fact that past research has largely relied on isolated personality traits with convenience samples from North American populations (Tenbrunsel \& Smith-Crowe, 2008 [26]; Volkema, 2004 [4]).

\subsection{Big Five Personality Traits and EQNS}

The Big Five Personality Model describes the most salient aspects of personality and enjoys increasing acceptance and popularity among personality psychologists. According to Barrick and colleagues (1991 [29], 2003 [30]), the five factors of the Big Five Model include emotional stability, extraversion, agreeableness, conscientiousness, and openness to experience. The first factor, emotional stability, is often associated with being calm, even-tempered, emotionally stable, and less reactive to stress. The second factor, extraversion, is associated with being sociable, assertive, talkative, and gregarious. The third factor, agreeableness, is associated with being courteous, flexible, trusting, cooperative, and tolerant. The fourth factor, conscientiousness, is often associated with being careful, responsible, and organized. The final factor, openness to experience, is associated with being imaginative, curious, original, and openminded.

The Big Five factors of personality are recovered from various personality measures in wide use, and they account for the shared variance in the trait adjectives of many languages (Digman \& Shmelyov, 1996 [31]; Hofstede \& McCrae, 2004 [32]). Evidence shows that the Big Five model of personality captures individual characteristics that are affective, experiential, and motivational (McCrae \& Costa, 1989 [33]). Studies also indicate that the Big Five traits are inheritable (Costa \& McCrae, 1995 [34]). Moreover, a considerable body of research has accumulated with compelling evidence for the robustness of the Big Five across different research designs (Goldberg, 1990 [35]), using different instruments (Conley, 1985 [36]; McCrae, 1989 [37]), in different cultures (Noller et al., 1987 [38]), and using ratings from different sources (Digman \& Inouye, 1986 [39]; Waston, 1989 [40]). However, despite the Big Five's popularity in various studies related to dispositional factors, few negotiation studies have used the Big Five to investigate personality and ethical attitudes and behaviors in the field of negotiations (Aslam \& Mian, 2011 [41]; Kalshoven, Den Hartog, \& De Hoogh, 2011 [42]; Mober, 1999 [43]), leading to inconclusive findings on the impact of dispositional factors on negotiation ethics. To help bridge the gap in negotiation ethics research, we will use the Big Five model in this study to examine the general relationship between personality and negotiation ethics in two cultures. One culture is from the West and one culture is from the East. The objective is to test personality effects in different contexts for a better understanding of ethical standards in negotiations and their variations across cultures. The general expectation is that the Big Five personality traits will have a significant impact on the perceived appropriateness and endorsement of EQNS in both cultures, with detailed hypotheses presented as follows. 
Emotional stability is associated with being stable, calm, even-tempered, unruffled by frustration, and less reactive to stress (McCrae \& Costa, 1989 [33]). Individuals high in emotional stability tend to have a positive self-concept, more self-esteem and self-acceptance, and tend to have less anxiety about how they appear to others. A few studies have related anxiety, low self-esteem, and self-acceptance to competitive negotiation behaviors (Ma \& Jaeger, 2005 [44]; Tedeschi et al., 1969 [45]; Williams et al., 1969 [46]), which is consistent with the notion that competitive behaviors are more likely to emerge among individuals who are high in anxiety. Low self-esteem individuals tend to be most anxious to compensate for their feelings of inadequacy by taking high rewards from others (Tedeschi et al., 1969 [45]). The underlying logic is that individuals who feel negatively towards themselves tend to be more anxious concerning how they behave in negotiations and will feel more of a need to prove themselves using competitive, exploitative tactics (Alexander et al., 1994 [47]), or ethically questionable negotiation strategies (Robinson et al., 2000 [3]; Volkema, 2004 [4]). On the contrary, negotiators who are emotionally stable are expected to exhibit less ethically questionable behaviors and are more ready to resort to appropriate tactics in negotiations (Ma, 2012 [48];Volkema, 2004 [4]). Therefore, it is expected in this study that negotiators with high emotional stability will be less likely to endorse EQNS in negotiations, and it is hypothesized that:

\section{H1. Emotional stability will be negatively related to the endorsement of EQNS.}

As an indicator of one's interpersonal assertiveness, gregariousness, and confidence in getting along with a variety of individuals (McCrae \& Costa, 1989 [33]), extraversion has been found associated with levels of individual impact on group interaction (Barry \& Friedman, 1998 [5]). Individuals high in extraversion are more inclined to develop friendly interpersonal relationships, spend more time with others, and enjoy being around people. The preferences for social interactions will lead extraverted individuals to consider the positive value attached to their situated identities and social image (Ma, 2012 [48]; McCrae \& Costa, 1989 [33]). Therefore, it is expected that extraverted individuals are less likely to endorse the use of EQNS in negotiations in order to maintain or protect their positive interpersonal relationships. It is thus hypothesized that:

H2. Extraversion will be negatively related to the endorsement of EQNS.

Agreeableness defines the tendencies to be cooperative, considerate, generous, altruistic, trusting, and trying to be liked by others (McCrae \& Costa, 1989 [33]). Agreeableness may be the dimension most closely tied to negotiations in the Big Five model (Barry \& Friedman, 1998 [5]). Research findings support that individuals high in agreeableness are linked to perceptions of and preferences for cooperative negotiation behaviors (Barry \& Friedman, 1998 [5]). In situations involving interdependence such as negotiations, agreeableness reflects a stable social value orientation that is trusting and cooperative. Consequently, agreeable negotiators are more likely to have a high trust perception of the other, and thus are less likely to endorse the use of EQNS in negotiations (Ma, 2012 [48]; McCrae \& Costa, 1989 [33]). The generous nature of agreeableness also has a clear potential to avoid the relentless pursuit of self-interest, which again suggests an inclination to use more ethical tactics and behaviors in negotiations from agreeable individuals. Therefore, it is hypothesized that:

H3. Agreeableness will be negatively related to the endorsement of EQNS.

Conscientiousness reflects being dutiful, reliable, thorough, responsible, self-disciplined, and aiming for achievement (McCrae \& Costa, 1989 [33]). Highly conscientious individuals are careful, self-disciplined, and have a desire for achievement. Past research has related conscientiousness to business negotiations, but the results are inconclusive. Some have claimed that conscientiousness is generally unrelated to the bargaining process (Barry \& Friedman, 1998 [5]), and others have claimed that conscientiousness is positively related to integrative negotiations (Ma \& Jaeger, 2005 [44]). It is reasonable to assume that, within the context of negotiations, organized and dutiful negotiators tend to make thorough preparation and carefully plan for negotiations. They make great effort to accomplish their tasks because they are achievement-oriented (Barrick, et al., 2003 [30]). As a result, they may be 
more likely to resort to ethically questionable tactics to help achieve their objectives. Empirical research has previously shown that individuals with strong needs for competitive success are more likely to use EQNS in negotiations (Ma, 2010 [1]). Thus, the following hypothesis will be tested in this study.

H4. Conscientiousness will be positively related to the endorsement of EQNS.

Openness to experiences has often been defined as having an active imagination, having a preference for variety, and willingness to entertain new ideas (Costa \& McCrae, 1995 [34]). Openness reflects the extent to which people are willing to make adjustments in notions and activities in accordance with new situations. Within the context of negotiations, open-minded negotiators are receptive to new ideas and solutions from the other sides and thus are more likely to take into consideration both sides' interests. They tend to behave in a cooperative manner, resulting in low endorsement of EQNS in negotiations (Ma, 2012 [48]). In addition, willingness to entertain new ideas and to make quick adjustment also means that open-minded negotiators are more likely to adjust their positions based on their perceptions of how their opponents behave in negotiations (McCrae \& Costa, 1989 [33]). When they perceive the other party has used EQNS, they will be more likely to quickly adjust their strategy and begin to use EQNS as well. Empirical studies have shown that a large percentage of negotiators act unethically and employ ethically questionable negotiation strategies intentionally or unintentionally. For example, Volkema and colleagues found that at least $80 \%$ of the participants in their study applied unethical strategies in negotiations (Volkema, 2004 [4]). Additionally, $\mathrm{O}^{\prime}$ Connor and Carnevale found that over $28 \%$ of their respondents provided distorted information to their counterparts in negotiations (O'Connor \& Carnevale, 1997 [49]). As a result, it is expected that negotiators high in openness who are flexible and ready to try new approaches will tend to endorse the use of EQNS in response to the frequent use of EQNS in negotiations. Therefore, the following hypothesis will be tested in this study.

H5. Openness to experiences will be positively related to the endorsement of EQNS.

\subsection{Cultural Context and EQNS}

Culture represents a unique character of a social group, which is a collective programming of the minds that distinguishes members of one group from another (Hofstede, 2001 [50]). It is widely accepted that cultural context affects ethical attitudes and behaviors (Lam \& Shi, 2008 [17]; Ma, 2010 [1]; Ma, Liang, \& Chen, 2013 [51]; Volkema, 2004 [4]). For instance, offering gifts and financial kickback in one culture is a normal practice in negotiations, but it may be viewed as bribery that is unethical or even illegal in another culture (Volkema, 1998 [8]). However, cultural differences in the relationship between personality traits and the endorsement of EQNS in business negotiations have not been carefully examined. Given that empirical studies have shown that the Big Five personality traits seem to be able to transcend culture (Hofstede \& McCrae, 2004 [32]), it is important to compare the impact of different cultural contexts on EQNS in order to provide more meaningful guidelines for negotiation practitioners in a global context.

The cultural context theory has been used in many cross-cultural studies to explain cultural differences in the communication process (Hall, 1976 [20]; Kirkbride et al., 1991 [52]; Ma, 2007 [25], 2010 [1]; Volkema, 1998 [8], 2004 [4]). In his seminal work Beyond Culture (Hall, 1976 [20]), Hall suggests that cultures can be characterized according to their communication styles as high-context cultures and low-context cultures. According to this theory, cultures differ in their degree to which cultural context affects the meaning individuals take from communication (Hall, 1976 [20]; Kittler, Rygl, \& Mackinnon, 2011 [21]). People from low-context cultures, such as Canadian culture, use explicit and direct language (mainly spoken and written words), and those from high-context cultures such as Chinese culture use implicit and indirect language, wherein words and phrases derive their meanings from contextual cues. As a result, negotiators from different cultures differ in their degree of sensitivity to communication contexts (Ma, 2007 [25], 2010 [1]), and the sensitivity to contextual cues affects the way negotiators 
perceive the particulars of a context, which further affects their use of negotiation strategies, even in a way that is incongruent to their dispositional characteristics if certain responses and tactics are more desirable in a particular situation (Banai et al., 2014 [22]; Stefanidis et al., 2013 [23]).

Such an interactive process will affect whether the negotiators use EQNS in business negotiations or not: In a low-context culture, individual negotiators tend to pay less attention to contextual cues and are more likely to behave in a way consistent with what is predetermined by their dispositional factors; in a high-context culture, individual negotiators pay closer attention to what is within the context, so their behaviors are less likely to reflect what is predetermined by their dispositional factors and are more related to the particulars of the specific context or situation (Ma, 2007 [25], 2010 [1]). For example, if they see that the use of certain unethical strategies will help achieve desirable outcomes in that particular situation based on a closer analysis of contextual cues, they are more likely to use these strategies even if their personality traits would tell them differently. Consequently, the relationship between individual negotiators' personality traits and negotiators' bargaining strategies will be stronger in a low-context culture than in a high-context culture. In this study, it is thus expected that, because of the high-context characteristic of Chinese culture, Big Five personality traits will have a weaker relationship with Chinese negotiators' EQNS in business negotiations. This does not apply to low-context Canadian culture though, for which it is predicted that Canadian negotiators' dispositional characteristics will have a stronger relationship with their endorsement of EQNS. Therefore, it is hypothesized that:

H6. The relationships between the Big Five personality traits and the endorsement of EQNS will differ in the two examined cultures: The relationship will be stronger in the low-context Canadian culture but it will be weaker in the high-context Chinese culture.

\section{Research Methods}

\subsection{Participants}

The participants of this study consisted of over 400 business professionals attending weekend programs at universities in their home countries with 170 from China and 258 from Canada (Anglophone Canada). They participated in this study on a voluntary basis. The participants from Canada had an average age of 24.8 (s.d. $=5.1$ ). The average working experience of Canadian participants was 3.4 years (s.d. $=4.6$ ), and $56 \%$ of them were male. The participants from China had an average age of 29.2 (s.d. = 6.0). The average years of working experience of Chinese participants were $5.4($ s.d. $=5.7$ ), and $46 \%$ of them were male (please refer to Tables 1 and 2). 
Table 1. Means, standard deviations, and correlations for the Canadian sample.

\begin{tabular}{|c|c|c|c|c|c|c|c|c|c|c|c|c|c|c|c|}
\hline Variables & Mean & s.d. & 1 & 2 & 3 & 4 & 5 & 6 & 7 & 8 & 9 & 10 & 11 & 12 & 13 \\
\hline 1. Gender & 1.44 & 0.50 & & & & & & & & & & & & & \\
\hline 2. Age & 23.8 & 5.11 & 0.05 & & & & & & & & & & & & \\
\hline 3. Experience & 3.49 & 4.59 & -0.00 & $0.76^{* * *}$ & - & & & & & & & & & & \\
\hline 4. Emotional stability & 3.19 & 0.70 & $-0.25^{* * *}$ & 0.02 & 0.00 & $(0.85)$ & & & & & & & & & \\
\hline 5. Extraversion & 3.24 & 0.74 & -0.00 & 0.04 & -0.07 & 0.09 & $(0.86)$ & & & & & & & & \\
\hline 6. Agreeableness & 3.74 & 0.59 & $0.21^{* * *}$ & $0.18^{* *}$ & $0.23^{*}$ & 0.05 & $0.27^{* * *}$ & $(0.80)$ & & & & & & & \\
\hline 7. Conscientiousness & 3.49 & 0.56 & 0.20 ** & $0.30^{* * *}$ & $0.29 * *$ & -0.06 & -0.04 & $0.27^{* * *}$ & (0.76) & & & & & & \\
\hline 8. Openness to experience & 3.61 & 0.54 & -0.13 & 0.09 & 0.03 & $0.16^{*}$ & $0.28^{* * *}$ & $0.32 * * *$ & $0.21^{*}$ & $(0.75)$ & & & & & \\
\hline 9. Traditional Competitive Bargaining & 2.78 & 0.88 & -0.12 & $-0.15^{* *}$ & $-0.19 *$ & 0.06 & -0.03 & $-0.16^{*}$ & 0.11 & $0.18 *$ & $(0.71)$ & & & & \\
\hline 10. Attacking the Opponent's Network & 1.82 & 0.84 & $-0.16^{*}$ & -0.05 & -0.21 * & -0.14 * & -0.00 & $-0.37^{* * *}$ & -0.14 * & $-0.16^{*}$ & $0.25^{* * *}$ & $(0.73)$ & & & \\
\hline 11. False Promises & 1.96 & 0.91 & -0.13 & $-0.15 *$ & $-0.20 *$ & -0.09 & 0.02 & $-0.36^{* * *}$ & $-0.14 *$ & -0.19 * & $0.25^{* * *}$ & $0.66^{* * *}$ & $(0.74)$ & & \\
\hline 12. Misrepresentation & 2.11 & 0.85 & $-0.14^{*}$ & -0.15 * & $-0.28^{* *}$ & -0.13 & -0.01 & $-0.34^{* * *}$ & -0.08 & -0.11 & $0.47^{* * *}$ & $0.70^{* * *}$ & $0.67^{* * *}$ & $(0.79)$ & \\
\hline 13. Inappropriate Information Gathering & 2.41 & 1.07 & $-0.24 * * *$ & -0.07 & $-0.22 *$ & -0.08 & -0.00 & $-0.31 * * *$ & -0.12 & -0.04 & $0.48^{* * *}$ & $0.63^{* * *}$ & $0.59 * * *$ & $0.68 * * *$ & $(0.79)$ \\
\hline
\end{tabular}

Note: $\mathrm{N}=258$. Variables were coded as follows: gender, $1=$ male, 2 = female; different negotiation strategies ranged from 1 to 5 , where 1 represents very inappropriate for use in negotiations, and 5 represents very appropriate for use in negotiations; the numbers in bold in the brackets along the diagonal are reliability coefficients (Cronbach alpha). ${ }^{*} p<0.05$ (2-tailed); ** $p<0.01$ (2-tailed); *** $p<0.001$ (2-tailed).

Table 2. Means, standard deviations, and correlations for Chinese sample.

\begin{tabular}{|c|c|c|c|c|c|c|c|c|c|c|c|c|c|c|c|}
\hline Variables & Mean & s.d. & 1 & 2 & 3 & 4 & 5 & 6 & 7 & 8 & 9 & 10 & 11 & 12 & 13 \\
\hline 1. Gender & 1.54 & 0.50 & - & & & & & & & & & & & & \\
\hline 2. Age & 29.2 & 6.00 & $-0.21 * *$ & - & & & & & & & & & & & \\
\hline 3. Experience & 5.44 & 5.76 & -0.10 & $0.90^{* * *}$ & - & & & & & & & & & & \\
\hline 4. Emotional stability & 3.11 & 0.63 & -0.06 & -0.02 & -0.02 & $(0.72)$ & & & & & & & & & \\
\hline 5. Extraversion & 3.21 & 0.52 & 0.12 & -0.23 ** & -0.14 & 0.14 & $(0.65)$ & & & & & & & & \\
\hline 6. Agreeableness & 3.55 & 0.48 & 0.09 & -0.14 & -0.05 & 0.06 & $0.30^{* * *}$ & (0.62) & & & & & & & \\
\hline 7. Conscientiousness & 3.50 & 0.55 & -0.06 & $0.23 * *$ & $0.26^{* * *}$ & $0.19 *$ & 0.02 & $0.21 * *$ & $(0.68)$ & & & & & & \\
\hline 8. Openness to experience & 3.44 & 0.57 & -0.03 & -0.07 & -0.00 & $-0.21 * *$ & $0.31 * * *$ & $0.19 *$ & $0.20 *$ & (0.64) & & & & & \\
\hline 9. Traditional Competitive Bargaining & 2.87 & 0.85 & -0.18 * & -0.11 & $-0.19 *$ & -0.14 & -0.03 & -0.05 & -0.02 & 0.04 & $(0.61)$ & & & & \\
\hline 10. Attacking the Opponent's Network & 2.49 & 0.80 & $-0.21 * *$ & 0.07 & 0.01 & $-0.22 * *$ & -0.19 * & $-0.33^{* * *}$ & -0.13 & -0.08 & $0.45^{* * *}$ & $(0.61)$ & & & \\
\hline 11. False Promises & 2.40 & 0.90 & -0.07 & $-0.21 * *$ & $-0.21 * *$ & $-0.21 * *$ & -0.09 & -0.15 & -0.06 & -0.06 & $0.45^{* * *}$ & $0.48^{* * *}$ & $(0.72)$ & & \\
\hline 12. Misrepresentation & 2.42 & 0.74 & -0.08 & $-0.17 *$ & $-0.20 * *$ & $-0.18 *$ & -0.06 & $-0.22 * *$ & $-0.16^{*}$ & -0.11 & $0.53^{* * *}$ & $0.64 * * *$ & $0.66^{* * *}$ & $(0.61)$ & \\
\hline 13. Inappropriate Information Gathering & 2.95 & 0.99 & -0.11 & -0.15 & $-0.17^{*}$ & $-0.18 *$ & -0.03 & -0.08 & -0.08 & 0.02 & $0.63^{* * *}$ & $0.42 * * *$ & $0.56^{* * *}$ & $0.56^{* * *}$ & (0.74) \\
\hline
\end{tabular}

Note: $\mathrm{N}=170$. Variables were coded as follows: gender, 1 = male, 2 = female; different negotiation strategies ranged from 1 to 5 , where 1 represents very inappropriate for use in negotiations, and 5 represents very appropriate for use in negotiations; the numbers in bold in the brackets along the diagonals are reliability coefficients (Cronbach alpha). ${ }^{*} \mathrm{p}<0.05$ (2-tailed); ${ }^{* *} \mathrm{p}<0.01$ (2-tailed); ${ }^{* * *} \mathrm{p}<0.001$ (2-tailed). 


\subsection{Variablesand Procedure}

In order to assess to the extent to which negotiators endorse the use of EQNS, the SINS (Self-reported Inappropriate Negotiation Strategies) scale, developed by Lewicki, Robinson, and colleagues for similar purposes, was used to collect information on 16 ethically questionable negotiation strategies (Lewicki \& Robinson, 1998 [12]; Robinson et al., 2000 [3]; Volkema, 1998 [8], 1999 [9], 2004 [4]). The SINS provides a very good platform to examine perceived appropriateness of a variety of bargaining strategies often used in negotiations (Volkema, 1998 [8], 1999 [9], 2004 [4]). It has been used in cross-cultural research and has been proven to be a valid scale even in the international context (Ma, 2010 [1]; Volkema, 1998 [8], 1999 [9], 2004 [4]; Volkema \& Fleury, 2002 [10]). In this questionnaire, participants are asked to assume that they are negotiating with an opponent for something that is very important. They are then to indicate on a five-point Likert scale how appropriate and acceptable it is to use the given tactic in each situation. The questionnaire states that there are no right or wrong answers regarding appropriate strategies or behaviors in negotiations. The participants are asked to be as honest as they can about what they consider is appropriate and acceptable to do in a negotiation, with anonymity assured for all participants.

The 16 items in the questionnaire were developed by Lewicki, Robinson, and colleagues (2000) and factored into five categories (Robinson et al., 2000 [3]; Lewicki \& Robinson, 1998 [12]) (please refer to Appendix A for the items). First, traditional competitive bargaining strategies include the following: making an exaggerated opening demand, making extreme demands to undermine the opponent's confidence, or conveying a false impression to put time pressure on the opponent. Second, attacking the opponent's network includes the following: an attempt to get the opponent fired so that a new person will take the place, undermine the opponent's confidence as a negotiator through his or her professional network, and threaten to embarrass the opponent through his or her professional network. Third, the false promises category includes the following: good things promised that you know you would not be delivered, a promise that your constituency will uphold the settlement while knowing they would probably violate the agreement later, and an offer to make future concessions that you would not follow through on in order to gain concessions from the opponent. Fourth, misrepresentation includes the following: misrepresent information to the opponent in order to strengthen your position, deny the validity of the opponent's information that might weaken your position, and misrepresent the process of negotiation as well as the nature of negotiation to your constituency. Finally, inappropriate information gathering includes the following: gaining information by paying your friends or others, gaining information about the opponent's position by hiring his/her friends or teammates, and gaining information about the opponent's position by giving expensive gifts.

The International Personality Inventory (IPI) developed by Goldberg (1990 [35]) to measure the Big Five factors was used in this study to assess participants' personality. The IPI scale is a 50-item short-version scale that provides a brief, comprehensive measure of the five dimensions of personality (please refer to Appendix A for the items used). It consists of five ten-item subscales that measure each of the five dimensions of personality in the Big Five. First, emotional stability includes sample items such as "I am relaxed most of the time." Second, extraversion includes sample items such as "I don't talk a lot." Third, agreeableness includes sample items such as "I sympathize with others' feelings." Fourth, conscientiousness includes sample items such as "I am always prepared." Finally, openness to experience includes sample items such as "I have a vivid imagination." Participants were asked to indicate on a 5-point scale how accurately each statement described the respondents, where $1=$ very inaccurately and $5=$ very accurately. Factor analysis also supported the five-factor structure in both cultures. The coefficient alphas for each of the dimensions were ranged from 0.62 to 0.86 between the two cultures (please refer to Tables 1 and 2 for detailed reliability data).

In Canada, the questionnaires were administered in English; in China, they were administered in Mandarin Chinese. All the questionnaires were translated into Chinese by bilingual colleagues of the authors in China. Finally, they were back-translated into English to ensure reliability and 
equivalence (Brislin, 1986 [53]). The participants filled out the questionnaires by themselves and at their convenience.

Hierarchical regression analyses were conducted to examine and compare personality effects on negotiation ethics in Canada and China. The relationships between personality traits and the perceived appropriateness or the endorsement of EQNS were then examined (please refer to Tables 3 and 4 and Figures 1 and 2 for results). The dependent variables consisted of the five categories of negotiation strategies from the SINS including traditional competitive bargaining, attacking the opponent's network, false promises, misrepresentation, and inappropriate information gathering. The independent variables consisted of the five personality traits as measured with the Big Five including emotional stability, extraversion, agreeableness, conscientiousness, and openness to experience. The effects of gender, age, education level, and working experiences were controlled for in this study.

Table 3. Regression results on the Big Five and the endorsement of ethically questionable negotiation strategies (EQNS) for the Canadian sample.

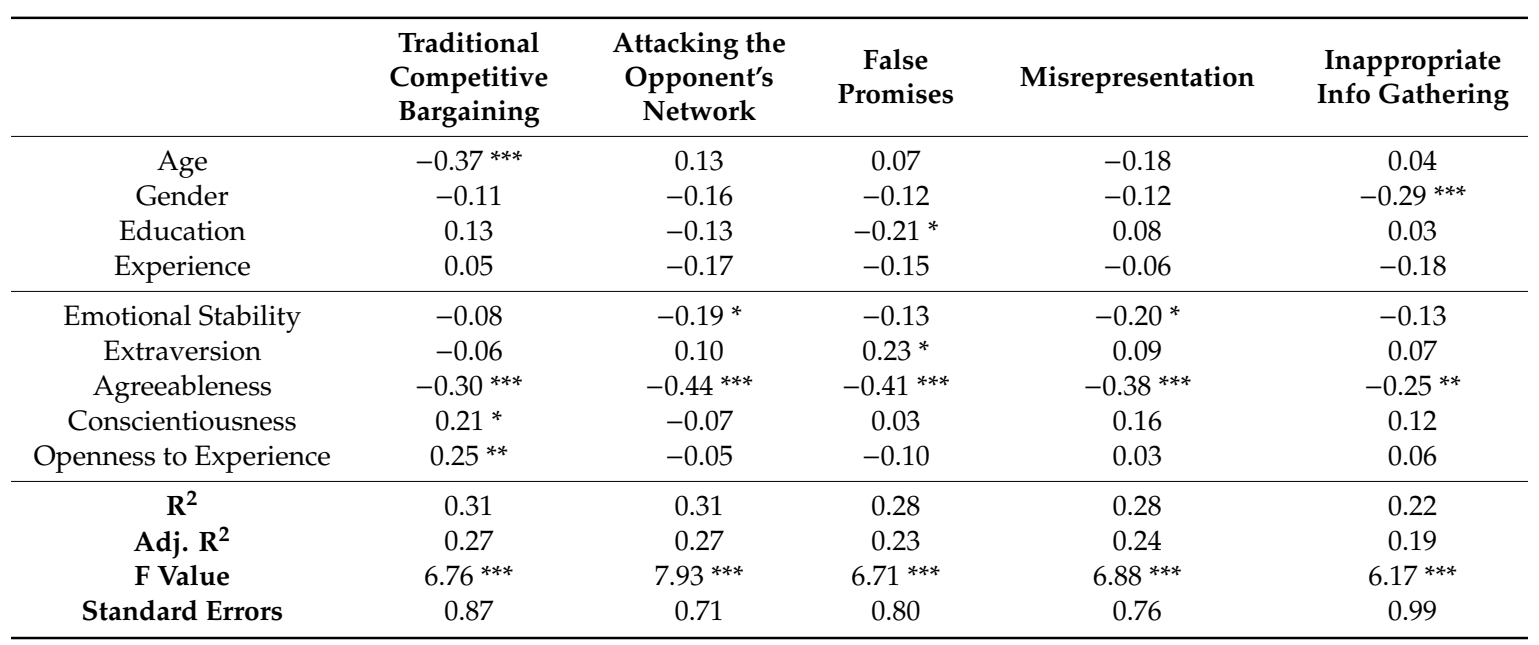

Note: $\mathrm{N}=258 .{ }^{*} p<0.05 ;{ }^{* *} p<0.01 ;{ }^{* * *} p<0.001$ (two-tailed).

Table 4. Regression results on the Big Five and the endorsement of EQNS for the Chinese sample.

\begin{tabular}{cccccc}
\hline & $\begin{array}{c}\text { Traditional } \\
\text { Competitive } \\
\text { Bargaining }\end{array}$ & $\begin{array}{c}\text { Attacking the } \\
\text { Opponent's } \\
\text { Network }\end{array}$ & $\begin{array}{c}\text { False } \\
\text { Promises }\end{array}$ & Misrepresentation & $\begin{array}{c}\text { Inappropriate } \\
\text { Info Gathering }\end{array}$ \\
\hline Age & 0.22 & 0.21 & -0.21 & -0.01 & -0.04 \\
Gender & $-0.17^{*}$ & -0.16 & -0.10 & -0.06 & -0.12 \\
Education & 0.03 & -0.10 & -0.02 & -0.05 & 0.03 \\
Experience & $-0.36^{*}$ & -0.20 & -0.01 & -0.18 & -0.14 \\
\hline Emotional Stability & $-0.18^{*}$ & $-0.19^{*}$ & $-0.21^{* *}$ & $-0.17^{*}$ & $-0.23^{* *}$ \\
Extraversion & 0.03 & -0.05 & -0.01 & 0.05 & 0.02 \\
Agreeableness & -0.04 & $-0.31^{* * *}$ & $-0.19 *$ & $-0.24^{* *}$ & -0.11 \\
Conscientiousness & 0.03 & -0.04 & 0.06 & -0.08 & -0.06 \\
Openness to Experience & 0.08 & 0.05 & 0.01 & -0.03 & 0.03 \\
\hline $\mathbf{R}^{2}$ & 0.10 & 0.20 & 0.13 & 0.12 & 0.08 \\
Adj. $\mathbf{R}^{\mathbf{2}}$ & 0.07 & 0.16 & 0.09 & 0.09 & 0.05 \\
F Value & $3.16^{* *}$ & $6.10^{* * *}$ & $3.59^{* * *}$ & $3.45^{* *}$ & $2.677^{*}$ \\
Standard Errors & 0.81 & 0.73 & 0.85 & 0.70 & 0.97 \\
\hline
\end{tabular}

Note: $\mathrm{N}=170 .{ }^{*} p<0.05 ;{ }^{* *} p<0.01 ;{ }^{* * *} p<0.001$ (two-tailed). 


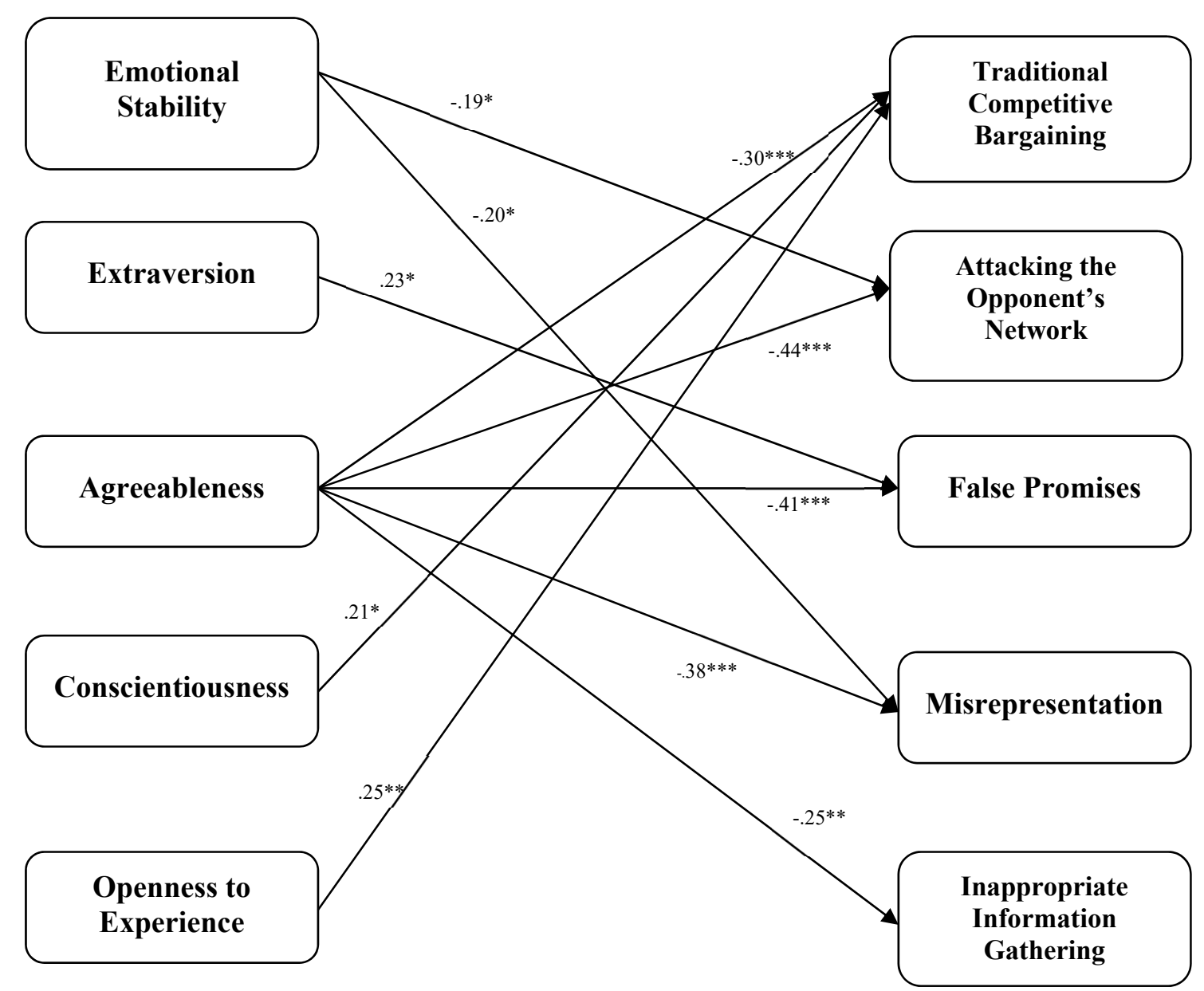

Figure 1. The impact of the Big Five traits on the endorsement of EQNS in Canada: $p<0.05 ;{ }^{* *} p<0.01$; *** $p<0.001$ (two-tailed).

\section{Results}

Tables 1 and 2 include means, standard deviations, and correlations among gender, age, experiences, personality traits, and different negotiation strategies. In general, the correlations reflect expected relationships and provide confidence that the measures functioned properly for the effects tested in this study. The relationships between demographic factors such as gender and age are consistent with the findings of other empirical studies. The reliability coefficients of different negotiation strategies and personality traits in both countries provide further evidence for the validity of the SINS scale and the Big Five scale used in this study (please refer to Tables 1 and 2).

From the mean scores of different categories of negotiation strategies, we can see that traditional competitive bargaining (e.g., exaggerate opening demands or make extreme demands to undermine the opponent's confidence) were considered the most appropriate negotiation strategies to use in Canada (mean $=2.78$, s.d. $=0.88$, on a five-point scale), followed by the inappropriate information gathering $($ mean $=2.41$, s.d. $=1.07)$. The other three categories of negotiation strategies were deemed considerably less appropriate to use in Canada, including misrepresentation, false promises, and attacking the opponent's network.

However, the endorsement of the same set of negotiation strategies was quite different in China. Instead of traditional competitive bargaining, the inappropriate information gathering (e.g., gain information by paying your friends or others; gain information about the opponent's position by giving expensive gifts) was considered the most appropriate strategies to use in negotiations in China (mean $=2.95$, s.d. $=0.99$, on a five-point scale). Traditional competitive bargaining strategies were 
considered the second most appropriate strategies in negotiations (mean $=2.87$, s.d. $=0.85$ ), followed by attacking the opponent's network, misrepresentation, and false promises.

In terms of personality effects on the endorsement of EQNS in negotiations, emotional stability was significantly and negatively related to all five categories of negotiation strategies in China and was statistically significant for attacking the opponent's network and misrepresentation in Canada. In other words, Chinese negotiators high in emotional stability are less likely to approve of the use of any kind of EQNS in negotiations, and Canadian negotiators high in emotional stability are less likely to endorse attacking the opponent's network or misrepresentation, which supports Hypothesis 1 (please refer to Table 3 and Figure 1 as well as Table 4 and Figure 2).

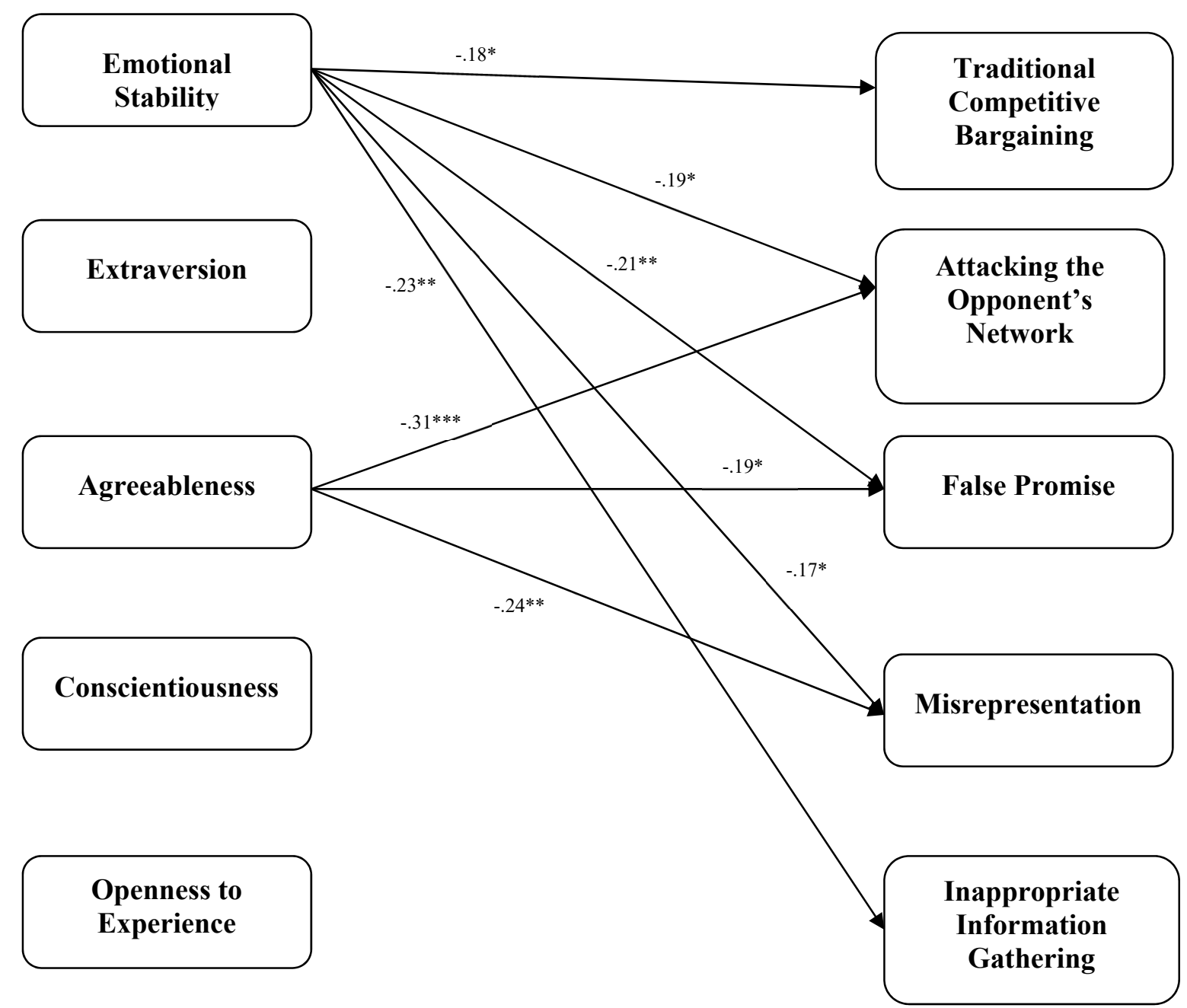

Figure 2. The impact of the Big Five traits on the endorsement of EQNS in China: ${ }^{*} p<0.05 ;{ }^{* *} p<0.01$; *** $p<0.001$ (two-tailed).

In addition, we also pooled the sample by combining a Canadian sample and a Chinese sample together with country as a dummy variable to explore the impact of personality effects on the endorsement of EQNS in negotiations (please refer to Table 5). The significance of the dummy variable of country in the regression results indicates that country as an important contextual variable affects how personality traits affect the endorsement of EQNS: except for the traditional competitive bargaining strategies, Canadian people are less likely than the Chinese people to endorse the use of EQNS including attacking the opponent's network, false promises, misrepresentation, and inappropriate information gathering, which is consistent with findings in similar studies (e.g., Ma, 2010 [1]). Moreover, when the country variable is controlled, the pooled sample also shows that both emotional stability and 
agreeableness are negatively related to the endorsement of EQNS across cultures, i.e., emotionally stable individuals or highly agreeable people are less likely to use any EQNS in both countries. Future research is encouraged to explore more international samples to examine whether this is universal across cultures.

Table 5. Regression results on the Big Five and the endorsement of EQNS for the combined sample.

\begin{tabular}{cccccc}
\hline & $\begin{array}{c}\text { Traditional } \\
\text { Competitive } \\
\text { Bargaining }\end{array}$ & $\begin{array}{c}\text { Attacking the } \\
\text { Opponent's } \\
\text { Network }\end{array}$ & $\begin{array}{c}\text { False } \\
\text { Promises }\end{array}$ & Misrepresentation & $\begin{array}{c}\text { Inappropriate } \\
\text { Info Gathering }\end{array}$ \\
\hline Age & $-0.21^{*}$ & 0.15 & -0.09 & -0.15 & -0.05 \\
Gender & $-0.18^{* *}$ & $-0.15^{* *}$ & $-0.13^{*}$ & -0.09 & $-0.21^{* * *}$ \\
Education & $0.16^{*}$ & -0.11 & -0.10 & 0.03 & 0.03 \\
Experience & $0.02^{*}$ & $-0.16^{*}$ & -0.11 & -0.07 & -0.14 \\
\hline Country (dummy) & 0.10 & $-0.29^{* * *}$ & $-0.25^{* * *}$ & $-0.22^{* *}$ & $-0.29^{* * *}$ \\
\hline Emotional Stability & $-0.15^{*}$ & $-0.18^{* * *}$ & $-0.17^{* *}$ & $-0.18^{* * *}$ & $-0.16^{* *}$ \\
Extraversion & $0.05^{* *}$ & 0.02 & -0.10 & 0.08 & 0.05 \\
Agreeableness & $-0.19^{* * *}$ & $-0.35^{* * *}$ & $-0.25^{* * *}$ & $-0.33^{* * *}$ & $-0.19^{* *}$ \\
Conscientiousness & $0.09^{* *}$ & -0.04 & 0.03 & 0.03 & 0.20 \\
Openness to Experience & $0.15^{*}$ & 0.01 & -0.01 & -0.01 & 0.06 \\
\hline R2 & 0.20 & 0.38 & 0.24 & 0.23 & 0.19 \\
Adj. R2 & $0.17^{* * *}$ & 0.36 & 0.21 & 0.21 & 0.17 \\
F Value & $8.06^{* * *}$ & $22.62^{* * *}$ & $11.49^{* * *}$ & $10.91^{* *}$ & $8.93^{*}$ \\
Standard Errors & 0.86 & 0.72 & 0.83 & 0.72 & 0.98 \\
\hline
\end{tabular}

Note: $\mathrm{N}=428 .{ }^{*} p<0.05 ;{ }^{* *} p<0.01 ;{ }^{* * *} p<0.001$ (two-tailed); Country as a dummy variable: $1=$ China, 2 = Canada.

Agreeableness was found negatively related to perceived appropriateness of all five categories of EQNS in Canada, and negatively related to three out of five categories of questionable negotiation strategies, including attacking the opponent's network, false promises, and misrepresentation of information in China. Therefore, Canadian negotiators high in agreeableness are less likely to approve of the use of any EQNS in negotiations, while Chinese negotiators high in agreeableness are less likely to consider it appropriate to employ strategies of attacking the opponent's network, false promises, or misrepresentation of information in negotiations. This is consistent with the prediction in Hypothesis 3.

Extraversion was found positively related to false promises in Canada, but not significantly related to any of the five categories of EQNS in China. Negotiators with high levels of extraversion in Canada, compared with those in China, are more likely to endorse false promises to their opponents. Hypothesis 2 is thus not supported, since extraversion is a significant predictor of the perceived ethicality of negotiation strategies in Canada, but not in China, even though this relationship-oriented trait seems to affect what strategies will be considered appropriate to use in negotiations within China.

Hypotheses 4 and 5 also receive partial support. Both conscientiousness and openness to experience were found positively related to traditional competitive bargaining strategies in Canada. Neither of them was significantly related to any of the five categories of EQNS in China. Therefore, Canadian negotiators high in conscientiousness are more likely to endorse the use of EQNS in negotiations to achieve their objectives. Additionally, Canadian negotiators high in openness to experience are also more likely to consider it appropriate to use the EQNS in response to the frequent use of EQNS in negotiations. However, this is not true in China. Neither conscientiousness nor openness was significant for the perceived appropriateness of EQNS in China.

A comparison of the relationships between the personality traits and the endorsement of EQNS in negotiations in Canada and China shows that personality effects in negotiation ethics for these two cultures are different as expected. Even though emotional stability and agreeableness are significant predictors of the perceived appropriateness of EQNS in negotiations for both cultures, the relationship between agreeableness and EQNS are much stronger in Canada than in China. In addition, all three traits including extraversion, conscientiousness, and openness are significant predictors of the possible 
use of EQNS in negotiations in Canada, but none of them have any impact on the possible use of EQNS in China, once again indicating a stronger influence of Big Five personality traits on the endorsement of EQNS in Canada than in China. Therefore, these results provide support for Hypothesis 6, which predicts that the relationships between the Big Five personality traits and the endorsement of EQNS will be stronger in Canada than those in China.

To further examine the different impact of Big Five personality factors on the endorsement of EQNS in the cultural contexts examined (Canada vs. China), we created a proxy variable-Context, with Canada as 2 to represent its low cultural context and China as 1 to represent its high cultural context-and then included the interactions of this proxy variable Context and Big Five personality factors in the regression analysis with two samples combined as one. The results confirmed our prediction: low cultural context strengthens the impact of emotional stability on traditional competitive bargaining strategies (standardized coefficient for the interaction item: $\beta=0.19, p<0.002$ ), the impact of emotional stability and agreeableness on false promising (standardized coefficient for the interaction item: $\beta=0.29, p<0.001 ; \beta=0.46, p<0.000$, respectively), and the impact of emotional stability on inappropriate information gathering (standardized coefficient for the interaction item: $\beta=0.28$, $p<0.001$ ). This regression result also shows that the relationships between the Big Five personality traits and the endorsement of EQNS are stronger in Canada than those in China, in support of Hypothesis 6. One interesting exception is that, while cultural context does not moderate the impact of Big Five personality factors on attacking the opponent's network, it actually weakens the impact of agreeableness on misrepresentation in Canada (standardized coefficient for the interaction item: $\beta=-0.23, p<0.001$ ). In other words, negotiators with high agreeableness in China are even more likely to avoid the use of EQNS in the high-context culture.

\section{Discussion and Conclusions}

The increasingly globalized world economy has created a strong need to understand different negotiation practices across the globe. This study began with the fact that, while personality had been very important in understanding the dynamics of negotiation encounters, personality effects on negotiation ethics were largely understudied. The tremendous individual differences in ethical attitudes and behaviors in negotiations had made it essential for a better understanding of dispositional influences on the perceived appropriateness of various EQNS. The relationship between personality traits and negotiation ethics deserved more research efforts. Then this study employed the cultural context theory and a well-accepted, comprehensive personality structure, the Big Five model, to explore personality effects on the perceived appropriateness of EQNS in Canada and China. The results of this study provided empirical support for previous research findings and identified key relationships between the Big Five personality traits and negotiation ethics. The findings will enrich our knowledge on negotiation ethics and personality, which is further able to advance contemporary studies on global business ethics and negotiation.

The results of this study provide empirical evidence for the impact of personality on negotiation ethics between two cultures. The results show that the Big Five personality traits strongly affect the endorsement of EQNS both in Canada and in China, but in different ways due to their cultural contexts. For Canadian negotiators, individuals high in conscientiousness, extraversion, and openness are more prone to use the EQNS, and individuals high in emotional stability and agreeableness are less likely to use them. For negotiators from China, only agreeableness and emotional stability significantly and negatively affect the endorsement of the EQNS. None of the other Big Five personality traits are significantly related to the perceived appropriateness of the EQNS. The common theme is that both emotional stability and agreeableness affect the perceived appropriateness of EQNS in these two cultures, but their impact is stronger in the low cultural context of Canadian culture. These findings could provide important insights for negotiation practitioners and international managers in training, selection, and intervention for effective negotiation practice. 
In addition to the different effects of Big Five personality factors on the endorsement of EQNS in Canada and China, the results of this study also showed that traditional competitive bargaining strategies were most accepted negotiation strategies among the five categories of ethically inappropriate strategies both in Canada and in China. This is congruent with many empirical studies conducted in the West (Lewicki \& Robinson, 1998 [12]; Ma, 2010 [1]; Rivers \& Lytle, 2007; Robinson et al., 2000 [3]; Volkema, 1998 [8], 1999 [9], 2004 [4]). The difference lied in that traditional competitive bargaining strategies were considered the most appropriate in Canada, but the second most appropriate in China. In other words, exaggerating the opening demand, hiding one's bottom lines, and pretending not to be in a hurry (traditional competitive bargaining) were largely considered ethically appropriate in negotiations by both the Chinese and Canadians.

The results of this study also revealed another critical difference between China and Canada in the perceived appropriateness of using EQNS in negotiations: Chinese negotiators considered the inappropriate information gathering (such as paying your friends or others to gain information or giving expensive gifts in exchange for information about the opponent's position) as the most appropriate strategies to use in negotiations, which is consistent with the Guanxi-oriented business practices in China. Guanxi business practice often requires expensive gifts and monetary rewards to maintain and reciprocate favors. This is a quite different attitude toward gift-giving and receiving from what is often practiced in the West (Ma et al., 2002 [54]).

The findings of this study have many implications. From a theoretical perspective, this study makes an important contribution to the literature of business ethics and negotiation ethics. It can help better explain personality and business ethics in a negotiation context. Future theory development in business ethics should take into consideration the important effects of personality on individuals' ethical attitudes and behaviors. While contemporary studies have begun to explore individual differences in business ethics, the research in this field is still limited, and none has been done in business negotiations. Our knowledge of negotiation ethics and personality in different countries remains fragmented, and our understanding about negotiation ethics in China is yet to be fully understood. This study helps narrow the gap by empirically testing the impact of personality on the perceived appropriateness of EQNS in Canada and China. To a certain extent, this study validates some of the Western findings in China and thus enriches the global negotiation and business ethics literature. In addition, the findings of this study are also important in helping to build a more sustainable business model. While unethical negotiation strategies may help negotiators gain benefits and reach favorable deals, using EQNS is a less sustainable practice in business and will hurt trust-based business models in the long run. The victims of the EQNS may also retaliate with more EQNS, and as a result, the overall sustainability of business practice suffers.

These findings also have important implications for policymakers who seek to establish a universally accepted code of ethics in international management. The results of this study show that both the Chinese and Canadian negotiators consider the traditional competitive bargaining strategy, such as exaggerating opening demand and creating false impression of urgency, to be more appropriate than other EQNS to use in negotiations. Furthermore, emotionally stable negotiators and agreeable negotiators seem to behave similarly in their ethical attitudes and behaviors in negotiations, which to some degree supports the efforts for a common set of code of ethical behaviors. Policymakers should consider these factors in their efforts to promote a common set of ethical standards for global business practice.

The findings of this study also have important practical implications for negotiation practitioners and international managers. The findings could help improve the effectiveness of training and selection of global negotiators by identifying the right candidates based on their personality types. With a good understanding on how personality factors affect the possible use of EQNS, negotiators could also assess their counterparts' personality and decide whether the other party is likely to employ EQNS and consequently respond with appropriate strategies in negotiations. Additionally, a better understanding of dispositional differences in the effects of personality factors on the perceived ethicality of EQNS can 
help international negotiators avoid feelings of frustration and distrust toward their opponents and thus avoid using tactics that might incite more anger and hatred from the others.

Future research could replicate this study to validate the results and further explore personality effects on the perceived appropriateness of different ethically questionable strategies in negotiations. However, this study also has limitations. It used convenience samples as participants, which limits the external validity in generalizing the findings of this study to other populations. The samples are not perfectly matched, which is the issue often associated with collecting data from different countries. The Chinese sample is older, includes more female participants, and has longer working experience. Future studies are encouraged to include more professional negotiators as participants and better matched samples in order to obtain more insights from experienced practitioners. Another limitation of this study is that this study uses the method of self-report to examine the perceptions of negotiation strategies, which almost always introduces self-serving biases in the results. Future research is encouraged to use alternative methods, such as observations of actual negotiation tactics employed in negotiations to explore individual differences in negotiation ethics. In addition, there are many other variables that may affect the relationship between personality and EQNS, yet their impact is not controlled for in this study. This study focuses on the relationship between personality and negotiators' attitudes, and future research in this line of research is urged to explore the relationships between personality traits, ethical attitudes, and actual negotiation behaviors and negotiation outcomes, including both economic outcome and relational outcome, in order to fully capture the dynamics of negotiation ethics and its relevant antecedents and consequences.

Author Contributions: Conceptualization: Z.M.; data curation: X.L.; formal analysis: X.L.; investigation: Z.M.; methodology: Z.M.; project administration: D.L.; resources: Z.M. and D.L.; supervision: D.L.; writing一original draft: Z.M.; writing一review \& editing: X.L.

Funding: This research received no external funding.

Conflicts of Interest: The authors declare no conflict of interest.

\section{Appendix A}

\section{The items used in the Self-reported Inappropriate Negotiation Strategies (SINS)}

1. Promise that good things will happen to your opponent if he/she gives you what you want, even if you know that you cannot (or won't) deliver these things when the other's cooperation is obtained.

2. Intentionally misrepresent information to your opponent in order to strengthen your arguments or position.

3. Attempt to get your opponent fired from his/her position so that a new person will take his/her place.

4. Intentionally misrepresent the nature of negotiations to your company in order to protect delicate discussions that have occurred.

5. Gain information about an opponent's negotiating position by paying your friends, associates, and contacts to get this information for you.

6. Make an opening demand that is far greater than what you really hope to settle for.

7. Convey a false impression that you are in absolutely no hurry to come to an agreement, thereby trying to put time pressure on your opponent to concede quickly.

8. In order to get concessions from your opponent now, offer to make future concessions which you know you will not follow through on.

9. Threaten to make your opponent look weak or foolish in front of a boss or others to whom he/she is accountable, even if you know that you won't actually carry out the threat.

10. Deny the validity of your opponent's information that weakens your negotiating position, even though that information is true and valid.

11. Intentionally misrepresent the progress of negotiations to your company in order to make your own position appear stronger.

12. Talk directly to the people who your opponent reports to, or is accountable to, and tell them things that will undermine their confidence in your opponent as a negotiator. 
13. Gain information about an opponent's negotiating position by cultivating his/her friendship through expensive gifts, entertaining or "personal favors."

14. Make an opening demand so high or so low that it seriously undermines your opponent's confidence in his/her ability to negotiate a satisfactory agreement.

15. Guarantee that your company will uphold the settlement reached, although you know that they will likely violate the agreement later.

16. Gain information about an opponent's negotiating position by trying to hire one of your opponent's teammates (on the condition that the teammate will bring you confidential information with him/her).

\section{The items used for International Personality Inventory (IPI)}

1. I am the life of the party.

2. I feel little concern for others.

3. I am always prepared.

4. I get stressed out easily.

5. I have a rich vocabulary.

6. I don't talk a lot.

7. I am interested in people.

8. I leave my belongings around.

9. I am relaxed most of the time.

10. I have difficulty understanding abstract ideas.

11. I feel comfortable around people.

12. I insult people.

13. I pay attention to details.

14. I worry about things.

15. I have a vivid imagination.

16. I stay in the background.

17. I sympathize with others' feelings.

18. I make a mess of things.

19. I seldom feel blue.

20. I am not interested in abstract ideas.

21. I start conversations.

22. I am not interested in other people's problems.

23. I get chores done right away.

24. I am easily disturbed.

25. I have excellent ideas.

26. I have little to say.

27. I have a soft heart.

28. I often forget to put things back in their proper place.

29. I get upset easily.

30. I do not have a good imagination.

31. I talk to a lot of different people at parties.

32. I am not really interested in others.

33. I like order.

34. I change my mood a lot.

35. I am quick to understand things.

36. I don't like to draw attention to myself.

37. I take time out for others.

38. I shirk my duties. 
39. I have frequent mood swings.

40. I use difficult words.

41. I don't mind being the center of attention.

42. I feel others' emotions.

43. I follow a schedule.

44. I get irritated easily.

45. I spend time reflecting on things.

46. I am quiet around strangers.

47. I make people feel at ease.

48. I am exacting in my work.

49. I often feel blue.

50. I am full of ideas.

\section{References}

1. Ma, Z. The SINS in Business Negotiations: Explore the Cross-Cultural Differences in Business Ethics Between Canada and China. J. Bus. Ethics 2010, 91 (Suppl. 1), 123-135. [CrossRef]

2. Rivers, C.; Lytle, A.L. Lying, cheating Foreigners!! Negotiation Ethics across Cultures. Int. Negot. 2007, 12, 1-28. [CrossRef]

3. Robinson, R.J.; Lewicki, R.J.; Donahue, E.M. Extending and testing a Five-Factor Model of ethical and unethical bargaining tactics: Introducing the SINS scale. J. Organ. Behav. 2000, 21, 649-664. [CrossRef]

4. Volkema, R.J. Demographic, cultural, and economic predictors of perceived ethicality of negotiation behavior: A nine-country analysis. J. Bus. Res. 2004, 57, 69-78. [CrossRef]

5. Barry, B.; Friedman, R.A. Bargainer characteristics in distributive and integrative negotiation. J. Personal. Soc. Psychol. 1998, 74, 345-359. [CrossRef]

6. Thompson, L. Negotiation Behavior and Outcomes: Empirical Evidence and Theoretical Issues. Psychol. Bull. 1990, 108, 515-532. [CrossRef]

7. Adler, R.S. Negotiating with Liars. MIT Sloan Manag. Rev. 2007, 48, 69-74.

8. Volkema, R.J. A comparison of perceptions of ethical negotiation behavior in Mexico and the United States. Int. J. Confl. Manag. 1998, 9, 218-233. [CrossRef]

9. Volkema, R.J. Ethicality in negotiations: An analysis of perceptual similarities and differences between Brazil and the United States. J. Bus. Res. 1999, 45, 59-67. [CrossRef]

10. Volkema, R.J.; Fleury, M.T.L. Alternative negotiating conditions and the choice of negotiation tactics: A cross-cultural comparison. J. Bus. Ethics 2002, 36, 381-398. [CrossRef]

11. O'Fallon, M.J.; Butterfield, K.D. A review of the empirical ethical decision-making literature. J. Bus. Ethics 2005, 59, 375-413. [CrossRef]

12. Lewicki, R.J.; Robinson, R. Ethical and Unethical Bargaining Tactics: An Empirical Study. J. Bus. Ethics 1998, $17,665-682$.

13. Lewicki, R.J.; Saunders, D.M.; Barry, B. Essentials of Negotiation, 5th ed.; McGraw-Hill/Irwin: Boston, MA, USA, 2007.

14. Adler, N.; Gundersen, A. International Dimensions of Organizational Behavior, 5th ed.; South-Western College Pub.: Boston, MA, USA, 2008.

15. Ma, Z. The status of contemporary business ethics research: Present and future. J. Bus. Ethics 2009, 90, 255-265. [CrossRef]

16. Ip, P.K. Is Confucianism Good for Business Ethics in China? J. Bus. Ethics 2009, 88, 463-476. [CrossRef]

17. Lam, K.; Shi, G. Factors affecting ethical attitudes in mainland China and Hong Kong. J. Bus. Ethics 2008, 77, 463-479. [CrossRef]

18. Lan, G.; Ma, Z.; Cao, J.; Zhang, H. A comparison of personal values of Chinese accounting practitioners and students. J. Bus. Ethics 2009, 88 (Suppl. 1), 59-76. [CrossRef]

19. Ghauri, P.; Fang, T. Negotiating with the Chinese: A social-cultural analysis. J. World Bus. 2001, 36, 303-325. [CrossRef]

20. Hall, E.T. Beyond Culture; Anchor: Garden City, NY, USA, 1976. 
21. Kittler, M.G.; Rygl, D.; Mackinnon, A. Beyond culture or beyond control? Reviewing the use of Hall's High-/Low-context concept. Int. J. Cross-Cult. Manag. 2011, 11, 63-82. [CrossRef]

22. Banai, M.; Stefanidis, A.; Shetach, A.; Ozbek, M.F. Attitudes toward ethically questionable negotiation tactics: A two-country study. J. Bus. Ethics 2014, 123, 669-685. [CrossRef]

23. Stefanidis, A.; Banai, M.; Richter, U. Attitudes towards questionable negotiation tactics in Peru. Int. J. Hum. Resour. Manag. 2013, 24, 826-852. [CrossRef]

24. Alas, R. Ethics in countries with different cultural dimensions. J. Bus. Ethics 2006, 69, 237-247. [CrossRef]

25. Ma, Z. Conflict management styles as indicators of behavioral pattern in business negotiation: The impact of contextualism in two countries. Int. J. Confl. Manag. 2007, 18, 260-279. [CrossRef]

26. Tenbrunsel, A.; Smith-Crowe, K. Ethical decision making: Where we've been and where we're going. Acad. Manag. Ann. 2008, 2, 545-607. [CrossRef]

27. Al-Khatib, J.; Rawwas, M.; Swaidan, Z.; Rexeisen, R.J. The ethical challenges of global business-to-business negotiations: An empirical investigation of developing countries' marketing managers'. J. Mark. Theory Pract. 2005, 13, 46-60. [CrossRef]

28. Banas, J.; Parks, M. Lambs among lions: The impact of ethical ideology on negotiation behaviors and outcomes. Int. Negot. 2002, 7, 235-260. [CrossRef]

29. Barrick, M.R.; Mount, M.K. The Big Five personality dimensions and job performance: A meta-analysis'. Pers. Psychol. 1991, 44, 1-26. [CrossRef]

30. Barrick, M.R.; Mount, M.K.; Gupta, R. Meta-analysis of the relationship between the five-factor model of personality and Holland's occupational types. Pers. Psychol. 2003, 56, 45-74. [CrossRef]

31. Digman, J.M.; Shmelyov, A.G. The structure of temperament and personality in Russian children. Soc. Psychol. 1996, 71, 341-351. [CrossRef]

32. Hofstede, G.; McCrae, R.R. Personality and culture revisited: Linking traits and dimensions of culture. Cross-Cult. Res. 2004, 38, 52-88. [CrossRef]

33. McCrae, R.R.; Coates, P.T. The structure of interpersonal traits: Wiggins's circumflex and the Five-Factor Model. J. Personal. Soc. Psychol. 1989, 56, 586-595. [CrossRef]

34. Costa, P.T., Jr.; McCrae, R.R. Solid ground in the wetland: A reply to Block. Psychol. Bull. 1995, 117, $216-220$. [CrossRef] [PubMed]

35. Goldberg, L.R. An alternative "description of personality": The Big Five factor structure. J. Personal. Soc. Psychol. 1990, 59, 1216-1229. [CrossRef]

36. Conley, J.J. Longitudinal stability of personality traits: A multitrait-multimethod-multioccasion analysis. J. Personal. Soc. Psychol. 1985, 49, 1266-1282. [CrossRef]

37. McCrae, R.R. Why I advocate the Five-Factor Model: Joint factor analyses of the NEO-PI with other instruments. In Personality Psychology: Recent Trends and Emerging Directions; Buss, D.M., Cantor, N., Eds.; Springer: New York, NY, USA, 1989; pp. 237-245.

38. Noller, P.; Law, H.; Comrey, A.L. Cattell, Comrey, and Eysenck personality factors compared: More evidence for the five robust factors. J. Personal. Soc. Psychol. 1987, 53, 775-782. [CrossRef]

39. Digman, J.M.; Inouye, J. Further specification of the five robust factors of personality. J. Personal. Soc. Psychol. 1986, 50, 116-123. [CrossRef]

40. Waston, D. Stranger's ratings of the five robust personality factors: Evidence of a surprising convergence with self-report. J. Personal. Soc. Psychol. 1989, 57, 120-128.

41. Aslam, M.S.; Mian, S.N. The impact of personality traits on academic dishonesty among Pakistan students. J. Commer. 2011, 3, 50-61.

42. Kalshoven, K.; Den Hartog, D.N.; De Hoogh, A.H. Ethical leader behavior and big five factors of personality. J. Bus. Ethics 2011, 100, 349-366. [CrossRef]

43. Moberg, D.J. The big five and organizational virtue. Bus. Ethics Q. 1999, 9, 245-272. [CrossRef]

44. Ma, Z.; Jaeger, A. Getting to yes in China: Exploring individual differences in Chinese negotiation styles. Group Decis. Negot. 2005, 14, 415-437. [CrossRef]

45. Tedeschi, J.; Burrill, D.; Gahagan, J. Social desirability, manifest anxiety, and social power. J. Soc. Psychol. 1969, 77, 231-239. [CrossRef]

46. Williams, C.D.; Steele, M.W.; Tedeschi, J.J. Motivational correlates of strategy choices in the Prisoner's Dilemma game. J. Soc. Psychol. 1969, 79, 211-217. [CrossRef] 
47. Alexander, J.F.; Schul, P.L.; McCorkle, D. An assessment of selected relationships in a model of the industrial marketing negotiation process. J. Pers. Sell. Sales Manag. 1994, 14, $25-41$.

48. Ma, Z. Dispositional determinants of the endorsement of ethically questionable negotiation strategies: Evidence from West and East. In Proceedings of the 19th International Conference for Promoting Business Ethics, London, UK, 4-16 August 2012.

49. O'Connor, K.M.; Carnevale, P.J. A nasty but effective negotiation strategy: Misrepresentation of a common-value issue. Personal. Soc. Psychol. Bull. 1997, 23, 504-515. [CrossRef]

50. Hofstede, G. Culture's Consequences: International Differences in Work-Related Values; Sage: Beverly Hills, CA, USA, 2001.

51. Ma, Z.; Liang, D.; Chen, H. Negotiating with the Chinese: Are they more likely to use unethical strategies? Group Decis. Negot. 2013, 22, 641-655. [CrossRef]

52. Kirkbride, P.S.; Tang, F.Y.; Westwood, R.I. Chinese conflict preferences and pp. negotiating behavior: Cultural and psychological influence. Organ. Stud. 1991, 12, 365-389. [CrossRef]

53. Brislin, R.W. The wording and translation of research instruments. In Field Methods in Cross-Cultural Research; Lonner, W.J., Berry, J.W., Eds.; Sage Publication: Newbury Park, CA, USA, 1986; pp. 137-164.

54. Ma, Z.; Wang, X.; Jaeger, A.; Anderson, T.; Wang, Y.; Saunders, D. Individual perception, bargaining behavior, and negotiation outcomes: A comparison across two countries. Int. J. Cross-Cult. Manag. 2002, 2, 171-184. [CrossRef]

(C) 2019 by the authors. Licensee MDPI, Basel, Switzerland. This article is an open access article distributed under the terms and conditions of the Creative Commons Attribution (CC BY) license (http://creativecommons.org/licenses/by/4.0/). 